\title{
ANÁLISIS DE LA POLÍTICA MONETARIA DEL BCE DESDE UN PUNTO DE VISTA AUSTRIACO
}

\author{
MARÍA MÉNDEZ ESCANDÓN*
}

Fecha de recepción: 28 de marzo de 2014.

Fecha de aceptación: 17 de febrero de 2015.

Resumen: Tras casi siete años desde el inicio de la Gran Recesión, el debate sobre cuáles son las medidas de política económica necesarias para volver a una senda de crecimiento equilibrado y sostenible todavía no ha cesado. En este contexto, son muchas las voces que reclaman un papel más activo de los bancos centrales, con medidas de política monetaria más contundentes. La Escuela Austriaca de Economía considera que el sistema monetario y financiero juega un papel fundamental, pero lo hacen con unos fundamentos radicalmente opuestos a los del resto de escuelas. El objetivo de este artículo es analizar la política monetaria única, llamando la atención sobre los beneficios que el euro ha supuesto para los países miembros, al mismo tiempo que se destacan los errores de diseño y fundamentación que tal sistema presenta desde un punto de vista de la economía austriaca.

Palabras clave: Política Monetaria, Unión Económica y Monetaria, Escuela Austriaca de Economía, Jesus Huerta de Soto.

Clasificación JEL: B53, E4, E5, E52, E58, E61.

Abstract: Seven years after the outset of the Great recession, the debate continues as to which economic policies are necessary to return to a state of balanced and sustainable growth. In this context, many voices demand more active participation of central banks, including more forceful implementation of monetary policy measures. The Austrian school of economic thought maintains that monetary and financial systems play a key role, but it does

* Máster en Economía de la Escuela Austriaca, Universidad Rey Juan Carlos. 
so from a foundation that is radically opposed to that of other economic schools. The goal of this article is to analyze Euro Area monetary policy, not only highlighting the benefits of the Euro for its member countries, but also emphasizing the fundamental errors in foundation and design of this policy from the perspective of the Austrian school.

Key words: Monetary Policy, Economic and Monetary Union, The Austrian School of Economics, Jesus Huerta de Soto.

JEL Classification: B53, E4, E5, E52, E58, E61.

\section{I \\ INTRODUCCIÓN}

El 1 de enero de 1999, doce países de la Unión Europea (UE) dieron un paso más en el proceso de integración europea, al renunciar a sus propias monedas, tipo de cambio y política monetaria, cediendo así su soberanía a un ente supranacional para conformar la Unión Económica y Monetaria (UEM). Desde su origen y hasta la actualidad, el objetivo fundamental del Eurosistema ha sido el mantenimiento de la estabilidad de precios, «salvaguardar el valor del euro».

El euro ha supuesto grandes beneficios para los países integrantes. Así, se le puede considerar, si bien de modo imperfecto, como un proxy del Patrón Oro, que ha permitido evitar los nacionalismos monetarios e imponer la necesaria reforma del sistema de bienestar actual (J. Huerta de Soto). ${ }^{1}$ No obstante, la política y visión que subyace bajo la UEM está fundamentada en la teoría económica convencional (la Escuela de Chicago, la Nueva Macroeconomía Clásica (NMC) y Nueva Macroeconomía Keynesiana $(\mathrm{NMK}))$, alejándose considerablemente de la Escuela Austriaca de Economía.

El objetivo de este trabajo es analizar la política monetaria del Banco Central Europeo (BCE) desde el punto de vista de los principales exponentes de la Escuela Austriaca de Economía: Carl

1 «En defensa del euro: un enfoque austriaco» (2012). 
Menger, Eugen Böhm-Bawerk, Ludwig von Mises, Friedrich A. Hayek y Jesús Huerta de Soto. Para ello, se divide la exposición en varias partes. En el segundo epígrafe se examinan las principales líneas de actuación y principios que inspiran a la política monetaria de la zona euro, haciendo hincapié en los diferentes fundamentos con respecto a los economistas austriacos. A continuación, se pasa a mencionar los beneficios que la UEM ha supuesto para los países miembro, destacando su aproximación al sistema de Patrón Oro. En la cuarta y última parte se describen brevemente las características que debería cumplir el sistema monetario actual para que, cumpliendo con los principios generales del derecho, se minimice la presencia y duración de los ciclos económicos, especialmente las fases recesivas, dadas las negativas consecuencias económicas y sociales que llevan aparejadas y sirva de base para un crecimiento equilibrado y sostenible en el largo plazo.

II

FUNDAMENTOS DE LA UEM Y ANÁLISIS CRÍTICO DE LA ESCUELA AUSTRIACA DE ECONOMIA

El debate originario sobre la idoneidad o no de llevar a cabo una unión monetaria se encuadra, en un primer lugar, en el debate sobre los tipos de cambio fijos o flexibles. Al albor de este debate, Robert Mundell ${ }^{2}$ y Marcus Fleming inician la teoría de las Áreas Monetarias Optimas en las que en un contexto estático, de funciones agregadas de oferta y demanda, tratan de estudiar bajo qué condiciones una unión monetaria puede resultar beneficiosa para dos o más economías, destacando factores como la necesidad de una libre circulación de factores y/o la perfecta flexibilidad de precios y salarios.

En un primer momento, los países europeos no cumplían estos requisitos. Sin embargo, otros economistas, encabezados por Paul De Grawe, alejándose de un contexto estático, resaltaron los

2 Mundell, R.A. (1961): «A Theory of Optimum Currency Areas», American Economic Review, vol. 51, n. 4 , pp. 657-665. 
beneficios que desde un punto de vista dinámico, que la UEM supondría para las economías integrantes. El conformar y completar un mercado único y un área financiera integrada, o los beneficios económicos de un banco central supranacional, con un mayor grado de independencia y por tanto mayor credibilidad a la hora de luchar contra la inflación sirvieron de empuje para que la UEM viera la luz. Se presuponía, además, que la unión monetaria, una vez formada, contribuiría a una mayor circulación de trabajadores y capitales, y a un aumento en la capacidad de ajuste de precios y salarios (cumpliendo así con los prerrequisitos argüidos por la teoría original de las áreas monetarias óptimas).

Con esta base, el BCE y el conjunto del Eurosistema ${ }^{3}$ se diseñaron a imagen y semejanza del Bundesbank alemán, y sobre las bases de la teoría económica neoclásica y monetarista, y alejada, por consiguiente, del enfoque de la Escuela Austriaca.

\section{Objetivos}

El principal objetivo del BCE, establecido así desde su creación en 1999 es la consecución de la estabilidad de precios. El Tratado de Lisboa refuerza este objetivo al ampliarlo a un objetivo no solo del Eurosistema, sino también de la UE. Adicionalmente, el Tratado establece que «sin perjuicio del objetivo de la estabilidad de precios, el Eurosistema debe de apoyar las políticas económicas en general con la visión de contribuir a los objetivos de la Unión, entre los que se encuentran el pleno empleo y un crecimiento económico equilibrado». 4

El objetivo de estabilidad de precios se ha fijado cuantitativamente, y si bien inicialmente se consideraba estabilidad de precios como un crecimiento interanual del índice armonizado de precios al consumo (IAPC) de la zona euro inferior al $2 \%$, en mayo de 2003 el Consejo de Gobierno del BCE precisó que «la estabilidad

\footnotetext{
${ }^{3}$ Formado por el BCE y los bancos centrales nacionales.

4 Art. 127, apartado 1 y artículo 282, apartado 2, del TFUE y artículo 2 de los Estatutos.
} 
de precios se buscaría tratando de mantener tasas de inflación por debajo pero cercanas al $2 \%$ a medio plazo». Con esta aclaración, el BCE pretende evitar no solo tasas de inflación, sino también la deflación. ${ }^{5}$

Desde un enfoque austriaco, se aprecian diversos errores. El primero, es entender la estabilidad de precios como el crecimiento del IAPC, que no tiene en cuenta la inflación de activos. Este error se habría hecho explícito con la gran recesión, en la que en España se alcanzaron crecimientos del IPC inferiores al 3-4\%, mientras que los activos inmobiliarios (no incluidos en el IAPC) llegaron a crecer a tasas del $18 \%$ en la fase previa a la crisis. Con todo, cabe mencionar que dentro del Six Pack ${ }^{6}$ (entró en vigor en 2011), el Procedimiento de Desequilibrios Excesivos (que veremos más adelante) sí va a tener en cuenta este aspecto, si bien el BCE no ha modificado la forma de medir el crecimiento de precios. En cuanto a la corrección llevada a cabo por el Consejo de Gobierno en el 2003 acerca de la idoneidad de que el crecimiento de los precios se sitúe por debajo pero cerca del $2 \%$, evidencia el miedo a la deflación que además se ha vuelto a agudizar recientemente. La Escuela Austriaca critica igualmente este temor. En primer lugar, la inflación es definida como un aumento de la oferta monetaria (Ludwig von Mises) y no como un crecimiento de los precios, siendo de manera análoga, la deflación una contracción de la cantidad de dinero u oferta monetaria. De este modo, en los años previos a la crisis (2001-2006), las ganancias de productividad existente en la economía no se tradujeron en una bajada de los precios, si no que la inflación producida por el BCE en forma de aumento de la base monetaria (con crecimientos del agregado monetario M3 en tasas cercanas al 7 y $12 \%$ entre 2005 y 2007, y lejos por tanto del objetivo marcado de 4,5\%) no permitió este descenso en los precios. ${ }^{7}$ Por el contrario, dio lugar a una distorsión de la estructura productiva, un exceso de

\footnotetext{
${ }^{5}$ http://www.bde.es/f/webbde/Secciones/SalaPrensa/ComunicadosBCE/ NotasInformativasBCE/03/Arc/Fic/pres520.pdf.

${ }^{6}$ Reforma de marco fiscal como consecuencia de la crisis económica y financiera, encaminada a alcanzar políticas fiscales prudentes.

7 FALTA
} 
inversión y endeudamiento que desembocó en la reciente crisis económica, como analizaremos posteriormente.

Por otro lado, J. Huerta de Soto ${ }^{8}$ señala que el temor actual a la deflación es infundado, y que estamos ante una deflación «buena», ${ }^{9}$ resultado de la inevitable contracción monetaria en un sistema de reserva de banca fraccionaria tras una época de auge y expansión. En el momento actual, el crecimiento estable de la masa monetaria en un contexto de aumento de bienes y servicios tendría como consecuencia aumentos de productividad reflejados en esta disminución de los precios, con el consiguiente aumento del poder adquisitivo de los ciudadanos. Muchos economistas, foros, y prensa hacen hincapié en los efectos nocivos que la deflación tendría sobre el consumo y el endeudamiento actual. En cuanto a la teoría de que la deflación retrasa el consumo, el fundamento es bastante endeble. Basta para ello observar la demanda de productos tecnológicos (como smartphones), cuya demanda no deja de aumentar pese a la caída de los precios. En cuanto al aumento del endeudamiento provocado por la deflación, se pasa por alto el ajuste en las expectativas de tipo de interés de los agentes, que disminuirían los incentivos a pedir préstamos, y se olvida además que si bien los deudores saldrían perjudicados, los acreedores saldrían beneficiados, y así el ahorro, clave en una economía de mercado para el crecimiento económico sostenible, también saldría reforzado.

\section{Principales características y principios de actuación}

La política monetaria del BCE se rige por una serie de principios, siendo los más destacables:

- Independencia: que tienen como consecuencia que ni el BCE, ni los bancos centrales nacionales, ni ningún miembro de de-

8 «La paranoia Antideflaflacionista», conferencia de clausura VII Congreso de Economía Austriaca (2014).

9 Para un mayor análisis, puede verse también Bagus, Phillip: «Five Common Errors about Deflation», Procesos de Mercado. Revista Europea de Economía Política, 3 (1) 2006: 105-23. 
cisión pueden solicitar ni aceptar instrucciones de ningún gobierno.

- Carácter preventivo y de miras al futuro (forward looking), debido a los desfases temporales y a la incertidumbre del marco en el que opera.

- Orientación hacia el medio plazo y no activismo: el Eurosistema no está obligado a corregir las desviaciones del corto plazo, considerando inevitables la volatilidad de la tasa de inflación a corto plazo.

- La política monetaria está basada en indicadores agregados del conjunto del área, y no de un país en particular.

- Transparencia, comunicando claramente los objetivos, la estrategia, evaluación y decisiones de política monetaria, con el objetivo de alcanzar un elevado grado de credibilidad. Estos serán prerrequisitos para poder influir y anclar las expectativas inflacionistas de los agentes.

- Prohibición de financiación del sector público por el BCE o los BCN: Queda prohibida la autorización de descubiertos o la concesión de cualquier otro tipo de créditos por el BCE y por los bancos centrales nacionales (BCN), en favor de instituciones órganos u organismos de la Unión, Gobiernos centrales, autoridades regionales o locales u otras autoridades públicas, organismos de Derecho público o empresas públicas de los estados miembros, así como la adquisición directa a los mismos de instrumentos de deuda por el BCE o los BCN.

\section{Estrategia de política monetaria}

El enfoque adoptado por el BCE para organizar, valorar y contrastar la información relevante a fin de evaluar los riesgos para la estabilidad de precios se articula sobre dos perspectivas analíticas complementarias conocidas como los «dos pilares»: el análisis económico y el análisis monetario.

- El análisis económico tiene como objetivo evaluar los determinantes de la evolución de los precios a corto y a medio plazo, centrándose en la actividad real y en la situación financiera de 
la economía. Tiene en cuenta el hecho de que la interrelación entre oferta y demanda en los mercados de bienes, servicios y factores influye significativamente sobre la evolución de los precios en estos horizontes temporales.

- El análisis monetario se centra en un horizonte temporal más amplio, y considera la relación existente a largo plazo entre dinero y precios. Esto se hace explícito en el anuncio de un valor de referencia cuantitativo para el crecimiento del agregado monetario amplio M3 (próximo al 4,5\%).

Con todo, este pilar se considera una referencia en complemento del pilar de análisis económico

El primer frente del ataque austriaco está basado en el uso de indicadores agregados, predicciones e ingeniería económica, esto es, en el método usado.

La mayor parte del estudio económico se ha basado en el método positivista, que tiene su origen en el filósofo y matemático francés Augusto Comte, y que parte del monismo metodológico, esto es, la defensa del método de las ciencias naturales, la física y las matemáticas en el resto de las ciencias. Para ello, gran parte del estudio de la economía actual parte de modelos basados en supuestos irreales (vaciado continuo de mercados, contexto estático, inmediata flexibilidad de precios y salarios...), tratando de establecer leyes objetivas que rijan el orden y el progreso social.

Frente a esto, la Escuela Austriaca defiende el dualismo metodológico, derivado de la necesidad de usar dos tipos de métodos diferentes: uno para las ciencias naturales y otro para las ciencias sociales. Hayek denomina así cientismo a la indiscriminada e indebida aplicación del método de las ciencias naturales en el campo de las ciencias sociales, economía y acción humana, debido en gran parte al éxito cosechado por la física y la biología durante la primera mitad del s. XIX y el deseo de demostrar su igualdad frente a estas. ${ }^{10}$ En este sentido, los economistas austriacos

10 F.A. Hayek, (Scientism and the Study of Society, part II): «During the first half of the nineteenth century the success of physical and biological sciences was such that they soon began to exercise an extraordinary fascination on those working in other fields, and who soon began to imitate their teaching and vocabulary. Thus the 
defienden un método lógico-deductivo o praxeológico, subjetivista, basado en axiomas generales. La ciencia económica es una ciencia social, es la ciencia de la acción humana, en la que los fenómenos son complejos y difíciles de aislar y simplificar.

La estrategia del BCE está basada en la economía convencional, fundamentada en el monismo metodológico, o ingeniería económica, pasando por alto el hecho de que es una ciencia social y por tanto su objeto de estudio es la función empresarial, el ser creativo, la acción humana que persigue unos fines utilizando para ello todos los medios que encuentra a su alcance.

Ludwig von Mises considera a las leyes económicas como leyes formales, universales y de tendencia. En las ciencias humanas todo son variables, solo se puede hablar de leyes de tendencia. No existen relaciones constantes ni uniformidades ni leyes de probabilidad, por lo que no se pueden realizar ni mediciones ni predicciones como las realizadas en el mundo de la naturaleza. Solo son posibles las guías representadas por las leyes económicas de tendencia y las regularidades plasmadas institucionalmente.

Jesús Huerta de Soto, Estudios de Economía Política, (2.ํe edición, 2004): «En el campo de la acción humana la estadística es siempre historia y las funciones y correlaciones solo describen lo que ocurrió en un determinado instante del tiempo pasado, en un área geográfica definida y como resultado de la acción de un número concreto de personas. La econometría no es más que un puro juego de niños que en nada contribuye a elucidar los problemas económicos de la realidad.»

La política monetaria del $\mathrm{BCE}$, se fundamenta en la teoría cuantitativa del dinero y la neutralidad del dinero en el largo plazo.

tyranny commenced which the methods and technique of the Sciences in the narrow sense of the term have ever since exercised over the other subjects. These became increasingly concerned to vindicate their equal status by showing that their methods were the same as those of their brilliantly successful sisters rather than by adapting their methods more and more to their own particular problems. And although in the hundred and twenty years or so, during which this ambition to imitate Science in its methods rather than its spirit has now dominated social studies, it has contributed scarcely anything to our understanding of social phenomena, not only does it continue to confuse and discredit the work of the social disciplines...». 
Siguiendo con la tradición de Jonh Locke y David Hume y la teoría cuantitativa del dinero $\left(\mathrm{M}^{*} \mathrm{~V}=\mathrm{P} * \mathrm{~T}\right)$, el BCE y los nuevos economistas neoclásicos, parten del supuesto de que el dinero es neutral en el largo plazo.

«The neutrality of money is a widely accepted and empirically validated proposition in the economic profession. In the long run, i.e. after all adjustments in the economy have worked through, a change in the quantity of money in the economy (all other things being equal) will be reflected in a change in the general level of prices and will not induce permanent changes in real variables such as real output or employment. A change in the quantity of money in circulation ultimately represents a change in the unit of account (and thereby the general price level) which leaves all other variables unchanged. This general principle, referred to as "the long-run neutrality" of money, underlies all standard macroeconomic thinking and theoretical frameworks.»

The Monetary Policy of the ECB (2011), published by the ECB. ${ }^{11}$

Esta visión presupone que la inflación afecta de manera uniforme y proporcional a todos los sectores de la economía, sin variabilidad en los precios relativos. Sin embargo, los economistas austriacos llaman la atención sobre como un aumento de la cantidad del dinero puesto en circulación se reparte entre los agentes de forma desigual, produciéndose cambios en el nivel general y relativo de precios, que dan lugar a un desajuste o descoordinación en la estructura de etapas de producción. La Escuela Austriaca estudia los efectos microeconómicos que una expansión monetaria produce sobre la estructura de la producción, proporcionando una base teórica sobre el capital, que permite diferenciar los cambios relativos en los precios en función de que los bienes se encuentren más o menos alejados del consumo. Para esto son esenciales las aportaciones de Carl Menger y Eugen Böhm-Bawerk respecto de la teoría del capital en el que la producción no es instantánea, sino que requiere un proceso de etapas sucesivas, y en función del ahorro disponible, los empresarios valorarán si pueden acometer o no proyectos que maduren en plazos superiores de tiempo.

11 http://www.ecb.europa.eu/pub/pdf/other/monetarypolicy2011en.pdf. 


\section{Mecanismos de transmisión}

El proceso a través del cual las decisiones de política monetaria afectan a la economía en general, y al nivel de precios en particular se conoce como el mecanismo de transmisión monetaria. El canal no es directo, al existir un sinfín de factores que afectan al nivel de precios, no solo las decisiones de política monetaria. Según el BCE: «It is an ongoing challenge for the central bank to identify the factors driving price trends in order to apply the appropriate monetary policy reaction».

El tipo de interés es uno de estos canales. «The chain of cause and effect linking monetary policy decisions with the trice level starts with a change in the official interest rates set by the central bank in its own operations (...). Given its monopoly over the creation of base money, the central bank can control the interest rates on its operations. Since the central bank thereby affects the funding cost of liquidity for banks, banks need to pass on these costs when lending to their customers». ${ }^{12}$

Los cambios en el tipo de interés también afectan a la oferta de crédito (canal del crédito). Un aumento del tipo de interés, dificulta la capacidad de repago de los prestatarios, restringiéndose así la concesión de créditos y por tanto la demanda de consumo e inversión. El BCE tiene en cuenta igualmente que bajos tipos de interés suponen un incentivo a la hora de asumir mayores riesgos por parte de los agentes. Por un lado porque aumentan el valor del colateral y de los activos, y por otro, porque convierte a los activos de mayor riesgo en más atractivos, a medida que los agentes buscan mayores rentabilidades. Esto conduce a una relajación en los requisitos otorgados a los préstamos, y a un excesivo crecimiento de la oferta de los mismos.

Del mismo modo, el canal del tipo de cambio y el de las expectativas de los agentes (influidas fundamentalmente por la credibilidad del banco central) afectan a la tasa de inflación.

Frente a esta concepción de los mecanismos de transmisión por parte del eurosistema, los economistas austriacos atacan los

12 https://www.ecb.europa.eu/mopo/intro/transmission/html/index.en.html 
fundamentos en los que se apoya dicho mecanismo en base a los siguientes argumentos:

a) Concepción del «tiempo» en la economía convencional.

Tradicionalmente, la teoría económica se sirve de modelos caracterizados por una visión estática, de equilibrio estacionario, donde los fines y medios están dados. La realidad económica se simplifica mediante funciones de optimización (normalmente maximización de producción, beneficio o utilidad) sujetas a unas restricciones, que son resueltas en base al uso de las matemáticas o de programas informático, dando lugar a soluciones de equilibrio general (iniciadas por Leon Walras en el siglo XIX). ${ }^{13}$

Los teóricos austriacos critican fuertemente esta concepción, al argumentar que la realidad es muy compleja, variante e incierta, y por tanto difícilmente simplificable a un proceso de optimización. Defiende que los empresarios actúan en competencia, entendida esta como un proceso de rivalidad, en el que la información no está dada, sino que se crea cada instante con cada nuevo proceso de actuación. ${ }^{14} \mathrm{El}$ tan utilizado supuesto de ceteris paribus jamás se da en la realidad, ya que el mundo real está caracterizado por el cambio, y es el cambio lo único que permanece constante. Es imposible recurrir a él para contrastar leyes económicas que son universales, de tendencia.

El entorno en el que tiene lugar la política monetaria está plagado de incertidumbre, y es por ello que para la economía austriaca, cualquier modelo basada en comportamientos constantes queda totalmente invalidado, siendo además inútil.

b) Hipótesis sobre las expectativas.

Del mismo modo, otro de los pilares fundamentales de la economía actual es la modelización de las expectativas de los agentes, en especial de la hipótesis de expectativas racionales (originalmente propuestas por Jonh F. Muth en 1961), que

13 Walras, L. (1877, printed 1954). Elements of Pure Economics. Harvard University Press

14 Vease Kirzner, Israel M. (1973): Competition and Entrepeneurship, The Universitiy of Chicago Press. Capítulo II: «The Entrepeneur». 
parten de que los agentes disponen de toda la información relevante para realizar sus predicciones, y que además no cometen errores sistemáticos. Frente a esto, para los teóricos austriacos, la información jamás está dada, si no que se crea y transmite continuamente.

En base a la hipótesis de expectativas racionales, diversos economistas desarrollaron modelos que inspiraron la política monetaria del BCE y de otros bancos centrales de economías avanzadas, destacando el Modelo de las Islas, de Robert Lucas, ${ }^{15}$ el Teorema de la Inefectividad de la política estabilizadora sistemática, de Sargent y Wallace ${ }^{16}$ o la Inconsistencia Dinámica de las Politicas Económicas, de Kidland y Prescott y Barro y Gordon. A grandes rasgos, todas ellas parten de una serie de características comunes: son modelos de equilibrio general, basados en la hipótesis de expectativas racionales, donde se cumplen la teoría cuantitativa del dinero en el largo plazo y el equilibrio continuo de los mercados. La principal conclusión que se extraen es la inefectividad de la política monetaria para afectar al ciclo económico, en especial la parte sistemática de la misma (que es anticipada por los agentes en base a sus expectativas), teniendo como consecuencia un proceso inflacionario si la política monetaria no atiende a ciertos criterios. En base a ello, recomiendan una política reglada, dirigida a reducir las tensiones inflacionistas, no discrecional, dotada de credibilidad y predecible y complementada con el uso políticas microeconómicas encaminadas a flexibilizar los mercados.

Los economistas austriacos, nuevamente, atacan profundamente esta concepción. El dinero no es neutral ni en el corto, ni en el medio, ni en el largo plazo. Muy por el contrario, produce efectos reales sobre la economía, ya que ante cambios en la política monetaria (o fiscal), por ejemplo, un aumento en la cantidad de dinero en circulación, llevará a que los empresarios,

15 Lucas, R.E., Jr. (1972). «Expectations and the Neutrality of Money». Journal of Economic Theory 4, 103-124.

16 Sargent, Thomas \& Wallace, Neil (1975). «"Rational” Expectations, the Optimal Monetary Instrument, and the Optimal Money Supply Rule». Journal of Political Economy 83 (2): 241-254. 
por su propia actividad que continuamente les impulsa a buscar beneficio, se aprovechen del nuevo dinero creado, acometiendo proyectos de inversión y comenzando así la fase expansiva del ciclo económico.

c) Tipo de interés y capital.

Para un nutrido grupo de economistas, (entre los que destaca John Bates Clark, Irving Fisher, George J. Stigler o Frank H. Knight), el tipo de interés de la economía viene determinado por la «productividad marginal del capital», un fondo permanente que consideran homogéneo y que de manera automática genera interés. El proceso productivo es por tanto instantáneo, sin distinguir en él las diferentes etapas de preferencia temporal. Esta concepción del capital es fuertemente criticada por Böhm-Bawerk, ${ }^{17}$ quién lo calificó de místico y mitológico, y por el resto de economistas austriacos. Conciben todo proceso productivo como el resultado de la cooperación de bienes de capital concretos, donde son los empresarios, las acciones humanas concretas, las que mediante procesos de prueba y error empresarial aumentan, amortizan o consumen los bienes de capital. De ningún modo es un proceso inmediato, sino que en él se van sucediendo los distintos planes de los empresarios, donde no existe un fututo objetivo y todo está «por hacer»y «nada por venir sin más».

La Escuela Austriaca contiene una teoría coherente de los tipos de interés, que define como la preferencia intertemporal por el consumo presente frente al consumo futuro, y que está en función de las preferencias de los agentes, el riesgo percibido y la pérdida esperada del poder adquisitivo del dinero. Consideran los tipos de interés como precios esenciales de la economía, y que deben ser por tanto fijados en un mercado libre para permitir la coordinación de las decisiones entre ahorradores e inversores.

En el seno de la UEM, por el contrario, el BCE basa su estrategia en la fijación del tipo de interés, basándose en predicciones y con el consiguiente peligro de desajustes en la coordinación

17 Böhm-Bawerk, E. (1882): Kapital und Kapitalzins: Positive Theorie des Kapitales. Verlag der Wagner'schen Universitats-Buchhandlung, Innsbruck 1889. 
de los agentes. De este modo, los tipos de interés extremadamente bajos en los años previos a la gran recesión, junto con un exceso de liquidez y el monopolio en la emisión de dinero por parte del BCE (y la Reserva Federal, entre otros bancos centrales), habrían sido el origen de la crisis reciente, provocando un fuerte boom expansivo, con una sobreinversión y una incorrecta asignación de recursos hacia sectores más capital intensivos, que sin embargo ha revertido y conducido a la situación actual (teoría del ciclo austriaco). ${ }^{18}$

\section{Política fiscal}

Con el objetivo de limitar los riesgos de estabilidad de precios, la UE ha acordado una serie de acuerdos institucionales, recogidos en el Tratado de Funcionamiento de la UE.

Entre estos se incluyen:

- Prohibición de monetizar el déficit público (Art. 123).

- Prohibición de acceso privilegiado a instituciones financieras (Art. 124).

- Clausula de no bail-out (Art. 125), que prohíbe los rescates financieros tanto por parte del BCE como por parte de la Unión (dichos rescates se permiten solo en casos de sucesos excepcionales que escapen al control de los gobiernos).

«The Union shall not be liable for or assume the commitments of central governments, regional, local or other public authorities, other bodies governed by public law, or public undertakings of any Member State».

- Pacto de Estabilidad y Crecimiento (Art. 121 y 126).

En 1992, el Tratado de Maastricht fijó las condiciones específicas que los países tendrían que cumplir si querían pasar a la

18 Para un mayor análisis, se recomienda la lectura de Huerta de Soto, J. (1986): «La teoría austriaca del ciclo económico», incluida en la obra Lecturas de Economía Política, Unión Editorial. Un estudio aún mas profundo se puede encontrar en la obra del mismo autor Dinero, crédito bancario y ciclos económicos, 5. edición (2011), Unión Editorial. 
tercera y última fase de creación de la UEM. Estos criterios, conocidos como los Criterios de Maastricht, e impulsados fundamentalmente por Alemania ante el temor inflacionista del resto de países, (especialmente los del sur de Europa) se establecieron sobre variables nominales ${ }^{19}$ : tipo de cambio, tasa de inflación, déficit y deuda pública, tipo de interés a largo plazo.

Sin embargo, estos criterios no eran suficientes para asegurar la futura estabilidad de una unión monetaria, por lo que en el año 1996, se firmó un pacto político que se incorporará un año más tarde al Tratado de Ámsterdam, el Pacto de Estabilidad y Crecimiento (PEC), cuyo objetivo es corregir el sesgo deficitario de los gobiernes de los estados miembros y fomentar la consolidación fiscal en los países pertenecientes a la UEM. Tres fueron los principales motivos en defensa de la adopción de este Pacto:

1. Ante una crisis económica y en un entorno de política monetaria única, la política fiscal se erige como un importante instrumento de estabilización. Es necesario, por tanto, que los países presenten cuentas públicas saneadas, que les den margen de maniobra y permitan un correcto funcionamiento de los estabilizadores automáticos.

2. Evitar políticas de expansión de deuda pública que puedan traducirse en inestabilidad financiera para el resto de los países miembros. ${ }^{20}$

3. Alemania, con su fuerte tradición anti-inflacionista tras las episodios hiperinflacioncitas sufridos tras la Segunda Guerra Mundial y temerosa de los efectos desestabilizadores que países con historial de déficits públicos pudieran tener sobre la estabilidad de la UEM, quiso incluir este elemento de disciplina fiscal.

19 Estabilidad del tipo de cambio en una banda de fluctuación del 15\% durante al menos dos años, una tasa de inflación que no superase en más de un punto y medio a la de la media con los tres países con una tasa de inflación más baja, un nivel de déficit y deuda pública inferiores al 3\% y al 60\% del PIB respectivamente, y unos tipos de interés a largo plazo que no superasen en más de dos puntos la media de los tres países con inflación más baja.

${ }^{20}$ Impidiendo que una política presupuestaria laxa de un país penalice al resto vía mayores tipos de interés, y poniendo en peligro, por consiguiente, el objetivo de control de la inflación. 
De este modo, por medio del PEC original, los países se comprometían a no incurrir en déficits excesivos. ${ }^{21}$ No obstante, el año 2003 supuso la muerte política de este Pacto debido a las críticas recibidas y sobretodo el rechazo del ECOFIN de no aplicar el procedimiento de déficit excesivo a Francia, Italia y Alemania, ${ }^{22}$ donde se ignoraba la recomendación de la Comisión. En 2005 entró en vigor una nueva versión del PEC, mucho más flexible y con mayores excepciones, que muchos criticaron por considerar que suponía un incentivo para políticas fiscales más expansivas, como posteriormente sucedió a raíz de la crisis iniciada en el 2007.

III BENEFICIOS DEL EURO

Con todo, el euro ha representado, para múltiples autores de la Escuela Austriaca grandes beneficios.

En primer lugar, Huerta de Soto señala como la adopción del euro ha sido un elemento disciplinador de las políticas fiscales de los distintos gobiernos, al perder estos su autonomía monetaria y por tanto la posibilidad de manipular su moneda local poniéndola al servicio de las necesidades políticas en cada momento. Con la crisis actual, la imposibilidad de devaluar la moneda ha desembocado en la aprobación de medidas de flexibilización de la economía, necesarias para ganar la competitividad perdida, tales como la revisión del sistema de pensiones, reformas para reducir el gasto público y una mayor flexibilización del mercado de trabajo.

Además, en un contexto ya de profunda crisis económica, la que se pone en duda el futuro y sostenibilidad del proyecto del euro, el Pacto de Estabilidad y Crecimiento experimentó una considerable transformación cuando se aprobó el conocido como «Six

${ }^{21}$ En el PEC original se entendía por déficit excesivo aquel que superase el 3\% del PIB. Solo se permitiría que lo sobrepase de forma excepcional y transitoria (si bien, aun así, este se debía de mantener cercano a dicho valor). Además, la ratio de deuda pública sobre el PIB no debía sobrepasar el $60 \%$.

22 El Canciller Alemán en aquel momento era Gerhard Schroeder, del SPD (partido socialdemocrata) y no del partido actual (CDU). 
Pack» (en vigor desde el 2011) ${ }^{23}$ seis instrumentos legislativos que suponen una profunda reforma de la supervisión de la política económica de los estados miembros. Las principales novedades son:

a) Establece una nueva «regla de gasto», por la cual la tasa de crecimiento del gasto público no puede exceder al crecimiento del PIB potencial a medio plazo a menos que esté acompañada por un aumento discrecional de los ingresos públicos. ${ }^{24}$

b) Exigencia a los estados miembros con deudas públicas superiores al $60 \%$ del PIB que avancen más rápidamente hacia la consolidación, quedando sujetos a sanciones en caso de que la reducción no se considere satisfactoria.

c) Se acortan los plazos y se da un mayor automatismo.

d) Marcos fiscales nacionales. Se introduce una directiva que pretende mejorar la calidad de los procesos presupuestarios de los estados miembros. ${ }^{25}$

Aparte de la reforma del PEC, se aprobaron también unos procedimientos de nueva creación:

e) Procedimiento de desequilibrios excesivos (con variables como la deuda publica...), que puede dar lugar a sanciones.

La justificación a la inclusión de este nuevo procedimiento se encuentra, por una parte, en la insostenibilidad de las divergencias que se estaban dando en la competitividad vía precio en un marco de moneda única, sin la posibilidad por tanto de devaluar. Igualmente, la elevada inflación de activos (especialmente burbujas inmobiliarias) y la intensa acumulación de deuda (interna y externa) observadas en los años previos a

23 Y complementado en 2013 con el Two Pack, cuyo objetivo es aumentar al coordinación en materia fiscal entre los estados miembro.

${ }^{24}$ El objetivo con esto es evitar lo sucedido en algunos países antes de la crisis, donde aumentan los ingresos públicos relacionados con factores extraordinarios, como por ejemplo, el crecimiento excesivo de activos inmobiliarios y financieros permita también un aumento del gasto público.

${ }^{25}$ Los objetivos son aumentar la coordinación en los procesos de elaboración entre el gobierno central y regional, establecer unos requisitos mínimos en la definición de los presupuestos nacionales y exigir análisis de sensibilidad. 
la crisis, da lugar a la consiguiente necesidad de establecer procedimientos que prevengan futuras ineficiencias en la asignación de recursos.

Adicionalmente, el euro ha supuesto otros beneficios, ya que al ser un tipo de cambio fijo entre los países miembro, ha permitido eliminar los costes de transacción (que se estiman en un 0,5\% del PIB europeo), ha reducido la incertidumbre en cuanto a las fluctuaciones del tipo de cambio (lo que ha permitido aumentar el comercio y la inversión), ha permitido profundizar en el mercado interior único (aumentando la transparencia de precios, que hace por tanto más difícil la discriminación de precios entre regiones), ha reducido las tasas de inflación y al ser el BCE un ente supranacional, es más difícil ejercer presión a nivel político (goza de una mayor autonomía).

En definitiva, muchos economistas pertenecientes a la Escuela Austriaca de Economía, consideran que la UEM, tal y como estaba contemplada en sus orígenes, se constituye como un sistema monetario más deseable por cuanto se aproxima más al Patrón Oro, eliminando los nacionalismos monetarios, e impidiendo, en cierto modo, la posibilidad de devaluación e impresión de papel moneda, obligando a los países a llevar a cabo políticas fiscales de restricción de gasto público y reformas profundas, incluida una revisión del sistema del estado de bienestar.

Con todo, las últimas medidas aprobadas por el BCE como respuesta a la Gran Recesión, tanto las convencionales (una rápida reducción de los tipos de interés) como las no convencionales, ${ }^{26}$ debilitarían el argumento de que el euro ha funcionado como un

${ }^{26}$ Entre las medidas no convencionales están:

- Refuerzo de liquidez y expansión de balances de bancos centrales: Credit Enhancing (FRFA), provisión de liquidez a distintos plazos, programa OMT (anuncio de programas de adquisición de deuda en el mercado secundario).

- Cambio en composición de balances: liquidez a plazos más largos (LTRO 6m y 1a, 2011-12: VLTRO 3 a), liquidez a largo plazo condicionada a expansión de crédito) y compra de valores, reducción de las reservas mínimas exigidas, ampliación del colateral

- Refuerzo de los anuncios expectativas forward guidance mediante los anuncios de comportamiento futuro de política monetaria.

— Y finalmente, y sobre todo, el «Quantitative easing» inicial en marzo de 2015. 
proxy del Patrón Oro, ya que finalmente el BCE habría cedido a las presiones de los gobiernos y grupos de interés comprando deuda pública en los mercados secundarios y recurriendo a la masiva inyección de liquidez al sistema bancario.

\section{IV}

\section{ALTERNATIVA AL SISTEMA ACTUAL: UN ENFOQUE AUSTRIACO}

La Escuela Austriaca de Economía ha estudiado y analizado el actual sistema monetario y financiero, atacando lo que a su juicio suponen graves errores de base, y denunciando las negativas consecuencias que el actual sistema fiduciario de papel moneda, sin un coeficiente de reservas del $100 \%$, produce sobre la economía. Muchas de las críticas han sido analizadas ya en los apartados anteriores, por lo que en el presente epígrafe se va a repasar brevemente el sistema monetario defendido por algunos autores austriacos, en concreto el defendido por Jesús Huerta de Soto y Murray Rothbard.

\section{El sistema monetario tiene que cumplir los principios tradicionales del derecho}

Desde un punto de vista jurídico y ético, es esencial que un sistema monetario cumpla con los principios generales del derecho, entendidos como aquel conjunto de normas e instituciones que de manera constante, repetitiva y pautada, a lo largo de los años, se han ido adaptando de manera evolutiva a los comportamientos de los seres humanos.

De este modo, la confusión entre el contrato de préstamo y el contrato de depósito (cuyo objeto es la guardia y custodia de lo depositado) ha servido para que los bancos, con el apoyo de los gobiernos (que han amparado regulatoriamente este privilegio) hayan vulnerado el derecho de propiedad, haciendo uso del dinero de los depósitos a la vista y no manteniendo el $100 \%$ del importe depositado (o tantundem) en caja. 
El sistema monetario actual vulnera, por tanto, el principio básico de guardia y custodia de los depósitos, al exigir unos coeficientes de reserva nimios (1\% en la UEM). Incluso los últimos esfuerzos llevados a cabo por la regulación de Basilea aplicable a las entidades de crédito (Basilea III) resultan totalmente insatisfactorios en este sentido, al centrarse en los requisitos de capital en vez de centrarse en el coeficiente de caja. Tampoco los requisitos de liquidez de Basilea III resuelven el problema ya que se circunscriben solo al descalce de plazos sin tener en cuenta los depósitos bancarios.

La existencia de un banco central como prestamista de última instancia y garante del sistema financiero, es otro aspecto del sistema actual que vulneraría el derecho de propiedad privada. Así, cuando el Banco Central rescata a una entidad financiera, está o bien utilizando el dinero de los impuestos para sufragarlo, o bien cobrando un impuesto encubierto en forma de mayor inflación, sin que haya sido aprobado por el Congreso.

A parte de esto, esta actuación genera un grave problema de riesgo moral, al suponer un incentivo para que los agente privados adopten posiciones más arriesgadas bajo la confianza de que el banco central acudirá en su rescate.

\section{El sistema monetario debe de evitar los ciclos económicos y propiciar un marco adecuado para el crecimiento duradero, equilibrado y sostenible en el largo plazo}

Los economistas austriacos han llevado a cabo un profundo estudio de los ciclos económicos, defendiendo que la expansión crediticia llevada a cabo por los bancos centrales, sin un respaldo de ahorro real, produce graves consecuencias sobre la estructura productiva y la economía en general.

Economistas como Carl Menger, Böhm-Bawerk (con su teoría del capital y del interés), y Ludwig von Mises han llamado la atención sobre el papel fundamental que el tipo de interés juega en la economía. De este modo, en un mercado libre, el tipo de interés sería el reflejo de la preferencia temporal de los agentes por el consumo presente, dependiente por tanto de sus valoraciones 
subjetivas, y que permite coordinar las decisiones entre ahorradores e inversores. Frente a esto, en economías como la actual, la fijación de los tipos de interés y determinación de la base monetaria por parte de un banco central monopolista, produciría una descoordinación entre las decisiones de prestamistas y prestatarios, dando lugar a una incorrecta asignación de los recursos, similar a la ocurrida desde el año 2001 hasta el 2007, cuando se inició la Gran Recesión. En este sentido, los autores austriacos van más allá que el resto de economistas liberales, resaltando la importancia que el mercado libre juega a la hora de determinar un precio tan esencial en una economía como es el tipo de interés, y las graves distorsiones que resultan de una fijación artificial del mismo. Esto supone una fuerte crítica al sistema monetario de planificación centralizado actual.

De este modo, un aumento en la oferta monetaria sin respaldo de ahorro previo, siempre llega primero a unos pocos (que salen ganando al poder comprar a los precios antiguos), redistribuye la renta (unos pocos se benefician a costa de la gran mayoría), distorsiona la estructura de precios relativos (unos precios suben más que otros) y por tanto distorsiona también la estructura productiva (provoca una mala asignación de recursos). Este proceso da lugar a un «alargamiento» ficticio e insostenible de los procesos productivos, que se hacen de forma indebida excesivamente intensivos en capital. Sin embargo, de manera espontánea e ineludible, el proceso inflacionario termina por revertir este proceso, dando paso a un proceso de desempleo, recesión y en donde se terminan por constatar todos los errores empresariales cometidos durante la fase de auge artificial.

\section{El Banco Central como monopolista}

La mayor parte de economías avanzadas cuentan con marcos regulatorio y organismos públicos cuyo objetivo es luchar con los monopolios. Sin embargo, el papel monopolista del banco central en la emisión de dinero es raramente cuestionado.

Dentro de la economía austriaca existen diversas teorías, pero cabe mencionar la propuesta que Jesús Huerta de Soto hace en su 
libro Dinero, crédito bancario y ciclos económicos, donde propone un sistema de total libertad de elección de moneda, la eliminación de las leyes de curso legal forzoso, estableciendo la completa libertad bancaria y permitiendo a los bancos establecerse con total libertad. Para su correcto funcionamiento, todos los agentes implicados (incluidos las entidades bancarias) deberían de someterse al cumplimiento de los principios generales del derecho, especialmente el del contrato de depósitos (coeficiente de caja al 100 por cien).

\section{El origen del dinero}

En un contexto como el actual de Gran Recesión, las demandas de medidas destinadas a dotar al sistema de una mayor liquidez deben de hacer reflexionar sobre una cuestión fundamental en una economía: la función del dinero, para que sirve, así como analizar si realmente, tan solo con la impresión de papel moneda, se puede solucionar la grave crisis económica. Fue el fundador de la Escuela Austriaca, Carl Menger, ${ }^{27}$ el primer economista en tratar de explicar el origen del dinero mediante una teoría apriorística deductiva. Así, el dinero surge para solucionar el problema de la doble coincidencia de necesidades, al resultar mucho más sencillo y rápido intercambiar los bienes por un bien generalmente aceptado, que por sus cualidades intrínsecas llegó a ser el oro.

De este modo, el dinero se origina de forma no intencionada a lo largo de un proceso evolutivo impulsado por multitud de seres humanos que buscan empresarialmente satisfacer sus necesidades (teoría evolutiva de las instituciones), y que permite la coordinación social y la especialización y profundización en la división del trabajo.

Sin embargo, la mayor parte de economistas estudian el dinero de forma agregada (al igual que la economía en general), pasando por alto en numerosas ocasiones sus aspectos microeconómicos, y confundiendo la demanda de dinero con la demanda de riqueza.

27 Menger, Carl (1892): «On the origins of Money», Economic Journal (volume 2). 


\section{$\mathrm{V}$ \\ CONCLUSION}

Tal y como fue concebido en sus orígenes, el euro se constituía como un arma contra los nacionalismos monetarios, y en cierto modo y como defiende Jesus Huerta de Soto, como un proxy del Patrón Oro. Así, la moneda única ha sido una excelente herramienta para evidenciar los problemas de lo que adolecen las viejas economías de la UE, y ha llevado a que, en el contexto de la grave crisis económica mundial y ante la incapacidad de poder devaluar la moneda directamente, la mayor parte de países hayan llevado a cabo importantes reformas encaminadas a una mayor flexibilización de sus economías. No obstante, los últimas medidas de política monetaria no convencional llevadas a cabo por el BCE para poder asistir a los países en dificultades, chocan frontalmente con los principios sobre los que se asienta el sistema monetario y financiero defendido por gran parte de los autores austriacos. En este sentido, el BCE y los bancos centrales nacionales todavía tienen un largo camino por recorrer para poder alcanzar dicho sistema, caracterizado por su cumplimiento de los principios generales del derecho, y capaz de evitar los periodos de auge y recesión que adolecen las economías. De este modo, la estrategia de política monetaria como tal no tendría que ser diseñada, porque simplemente seria inexistente. Sería el mercado, y las valoraciones subjetivas de los agentes sometidos a un estricto cumplimiento de los principios generales del derecho los que se encargarían del correcto funcionamiento del mismo.

\section{REFERENCIAS BIBLIOGRÁFICAS}

Alonso Neira, M.A., Bagus, P. y Romero Ania, A. (2013): «Una ilustración empírica de la teoría austriaca del ciclo económico: el caso de Estados Unidos, 1988-2010», Investigación Económica, vol. LXXII, n. ${ }^{\circ}$ 285, pp. 41-74.

Alonso Neira, M.A, Bagus, P. y Rallo, J.R. (2011): «Teorías del ciclo económico: Principales contribuciones y análisis a la luz 
de las aportaciones de la Escuela Austriaca de Economía», Revista ICE, n.o 858, pp. 71-87.

Bagus, P. (2006): «Five Common Errors about Deflation», Procesos de Mercado: Revista Europea de Economía Política, vol. 3 (1), pp. 105-23.

- (2010): The Tragedy of the Euro, Auburn, Alabama, Ludvig von Mises Institute.

BÖHM-BAWERK, E. (1882): Kapital und Kapitalzins: Positive Theorie des Kapitales. Verlag der Wagner'schen Universitats-Buchhandlung, Innsbruck 1889. [Traducción al español Teoría positiva del capital, Unión Editorial y Ediciones Aosta, Madrid, 1998].

FIsHeR, I. (1911): The Purchasing Power of Money: Its determination and Relation to Credit Interest and Crisis, Nueva York, Macmillan.

FRIEDMAN, M. (1959): Un programa de estabilidad monetaria y reforma bancaria, Nueva York, Fordham University Press [Ediciones Deusto, Bilbao, 1970].

Friedman, M. y Schwartz, A.J. (1971): A Monetary History of the United States 1867-1960, Princeton, Princeton University Press.

Garrison, R.W. (2001): Time and money: The Macroeconomics of Capital Structure, Londres y Nueva York, Routledge.

HAYeK, F.A. (1931): Precios y producción: Una explicación de las crisis de las economías capitalistas, Madrid, Unión Editorial y Ediciones Aosta [1996].

- (1933): Monetary Theory and the Trade Cycle, Clifton, Augustus M. Kelley.

- (1943): «Economics and Knwledge», Economica, vol. 10, n.․37, p. 268.

- (1948): Individualism and Economic Order, Chicago, The University of Chicago Press.

- (1978): La desnacionalización del dinero, Madrid, Unión Editorial [1983].

HUERTA DE SOTO, J. (1986-1987): Lecturas de economía política, vols. I-III, Madrid, Unión Editorial [4. a edición, 2012].

- (1992): Socialismo, cálculo económico y función empresarial, Madrid, Unión Editorial [4. a edición, 2010].

- (2000): La Escuela Austriaca: Mercado y creatividad empresarial. Madrid, Edit. Síntesis. 
- (2011a): Dinero, crédito bancario y ciclos económicos, Madrid, Unión Editorial [5. a edición, 2011].

- (2012): «En defensa del Euro: un enfoque austriaco (Con una crítica a los errores del B.C.E. y al intervencionismo de Bruselas)». Ludvig von Mises Institute.

Menger, C. (1950): Principles of Economics, Illinois, Free Press of Glencoe.

Mises, L. von (1912): Teoría del dinero y del crédito, Madrid, Unión Editorial [3." edición, 1997].

- (1949): Human Action: A Treatise on Economics, Yale University Press. [Ludwig von Mises Institute, Auburn, Alabama,1998] RothbARD, M.N. (1993): Man, Economy, and State: a Treatise on Economic Principles, Auburn Univeristy, Ludwig von Mises Institute. Segura, J. y Rodríguez Braun, C. (1998): La economía en sus textos, Madrid, Taurus. 